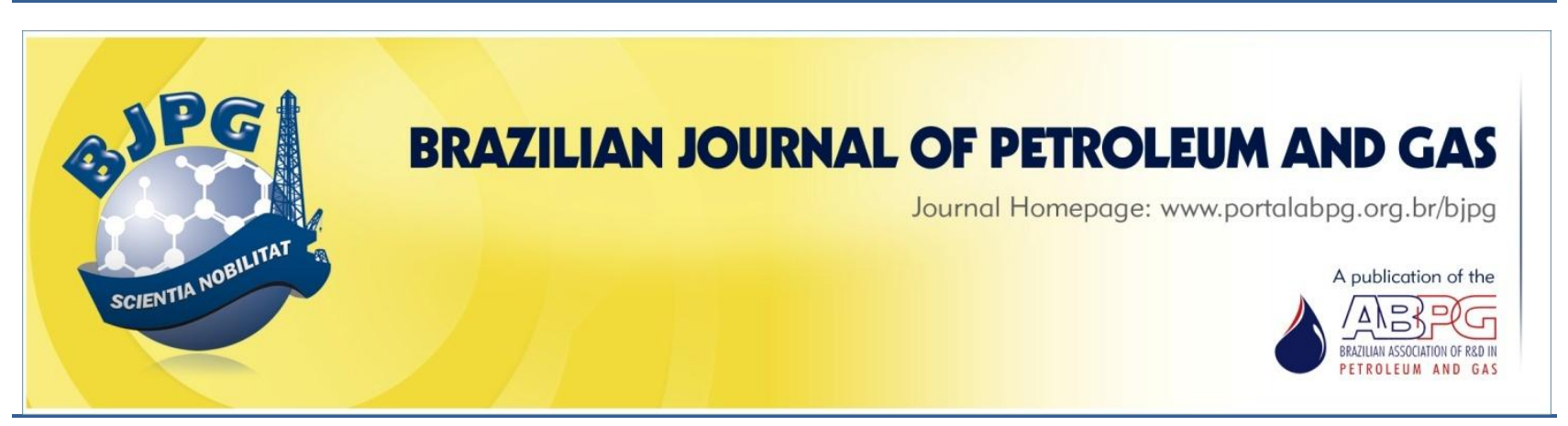

\title{
ANALYSIS OF DEPOSITION FROM PARAFFIN-SOLVENT MIXTURES UNDER TURBULENT FLOW
}

\author{
${ }^{a, b}$ Aum, Y. K. P. G. ${ }^{1}$; ${ }^{\text {Aum, P. T. P; }}{ }^{\text {d }}$ Fonseca, J. L. C.; ${ }^{a}$ Barros Neto, E. L.;
}

a Dantas Neto, A. A.; ${ }^{a}$ Dantas, T. N. C.

a Department of Chemical Engineering, Federal University of Rio Grande do Norte - UFRN, Natal, RN, Brazil

${ }^{b}$ Department of Chemical Engineering, Federal University of Amazonas - UFAM, Manaus, AM, Brazil

c Department of Petroleum Engineering, Federal University of Rio Grande do Norte - UFRN, Natal, RN, Brazil

${ }^{d}$ Institute of Chemistry, Federal University of Rio Grande do Norte - UFRN, Natal, RN, Brazil

Received: 18.12.2015 / Revised: 25.02.2016 / Accepted: 01.03.2016 / Published on line: 06.04.2016

\begin{abstract}
Paraffin deposition is a common problem in the flow of paraffinic and heavy oils. Solids deposition in the pipe wall results in rising process costs due to an increase in energy cost of pumping, a decrease in production, an increase in pressure on the line and risk pipeline blockage. In this work, a simulator was developed to allow the analysis of paraffin deposition under different operating conditions, to understand the influence of the variables (inlet and external temperatures, wax appearance temperature, composition, and time) on paraffin deposition under turbulent flow. A mathematical model for quantitative prediction of wax deposition for paraffin-solvent mixtures was proposed. The methods used in the estimation of physical, thermal, and transport properties of mixtures were suitable when compared with literature data. The simulator calculated the profiles of temperature and thickness of the deposit, with consistent results. The results showed the important role of operating temperatures in paraffin deposition.
\end{abstract}

\section{KEYWORDS}

simulation; paraffinic deposits; petroleum; modeling; flow assurance

\footnotetext{
${ }^{1}$ To whom all correspondence should be addressed.

Address: Federal University of Rio Grande do Norte, Dept. of Chem. Eng., Campus Universitário, Natal-RN, Brazil. ZIP Code: 59078-970 | Telephone: +55 84 99977-5922 |e-mail: yanne@ufam.edu.br doi:10.5419/bjpg2016-0002
} 


\section{INTRODUCTION}

Petroleum (or crude oil) consists of a mixture of saturated hydrocarbons (paraffins, isoparaffins, naphthenes), aromatics, resins, and asphaltenes. In the reservoir, where temperatures vary from 70 to $150^{\circ} \mathrm{C}$ and pressures are higher than 2000 psi, paraffin molecules are dissolved in crude oil. As the petroleum flows within pipes at the bottom of the sea (at temperatures around $4^{\circ} \mathrm{C}$ ), heat losses promote the decrease of temperature below the clouding point or WAT (wax appearance temperature). At this point, the deposition solubilized paraffin on the colder pipe wall starts. This process of deposition is one of the main problems for flow assurance, as it restricts petroleum flow, due to the resultant piping losses.

Recent oil discoveries in the Brazilian coast present challenges related to flow assurance, as they are located at depths of $2000 \mathrm{~m}, 350 \mathrm{~km}$ far from shore: the explored oil, as a consequence, has to flow through long distances, at low temperatures, overcoming high pressure differentials. High piping losses imply the increase of operational and repair costs. In most critical cases, the continuous deposition of paraffin may result in layers with thicknesses sufficient to obstruct tabulation, causing production interruption (Akbarzadeh \& Zougari, 2008).

Several mathematical models were proposed to describe the paraffinic petroleum flow, associated to the deposition of solid paraffin on pipe inner surface (Ramirez-Jaramillo et al., 2004; Correra et al., 2007; Huang et al., 2011a; Wang \& Huang, 2014). Additionally, significant efforts have been employed to study and model paraffin deposition, involving thermodynamics, heat/mass transfer, crystal growth, and fluid dynamics (Eskin et al., 2013; Cabanillas et al., 2016; Soedarmo et al., 2016).

Bagatin et al. (2008) compared different commercial softwares to experimental data related to the deposition of paraffins and concluded that the models reported in the literature still presented some limitations, many of them related to the practical reliability of their previsions. These limitations seem to be a consequence of an incomplete knowledge of important physicochemical parameters related to the mechanism of deposition, resulting in fitting of poorly defined models to experimental data.

The scarcity of detailed studies with data from oil fields results in a tremendous obstacle for the certification of deposition models for real situations. As a consequence, the need for developing alternative deposition models and softwares capable to forecast deposition process in different situations subsides. The aim of this work is to fulfill part of these needs, by developing a software capable of describing paraffinic deposition during a turbulent flow using a model and testing it with data from an oil field. A graphical interface was created to input data and the model equations proposed were solved using MATLAB 7.4. The simulator developed was used to analyze the effects of inlet temperature, external temperature, WAT, time, and composition of paraffin-solvent mixtures on paraffinic deposition.

\section{MATERIALS AND METHODS}

\subsection{Methodology}

The work was carried out in four steps, all of them depicted in Figure 1 and detailed below:

- Step 1: Application of semi-empiric methods to estimate the properties of pure components and paraffin-solvent mixtures.

- Step 2: Calculation of solid-liquid equilibrium of paraffin-solvent mixtures for the determination of WAT and paraffin solubility curve.

- Step 3: Presentation of a mathematical modeling of the process of deposition during turbulent flow in a pipe taking into account mass and heat transfer phenomena in a steadystate regime.

- Step 4: Development and execution of software with graphical interface to allow the simulation of different conditions of operation. As a result, one can achieve the simulation to better understand the influence of all the important variables on the deposition process (inlet temperature, external temperature, WAT, mixture composition, and time). 


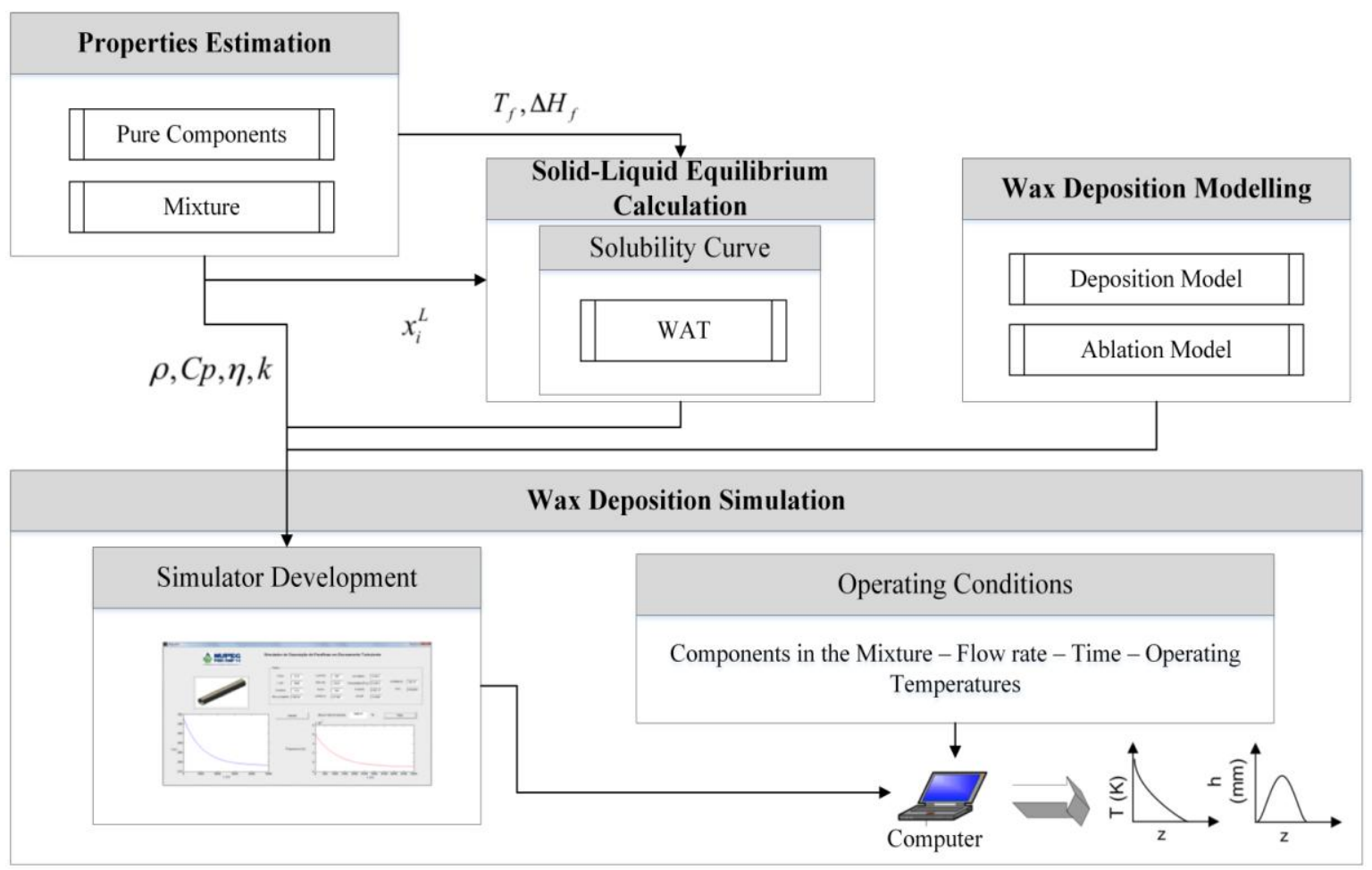

Figure 1. Scheme depicting the steps involved in the development of this work.

\subsection{Paraffin-solvent mixtures}

The mixture components (shown in Table 1) were chosen to study the influence of paraffin molar mass on deposition during flow: the paraffinic chain size varied from $\mathrm{C}_{34}$ to $\mathrm{C}_{40}$, maintaining $C_{15}$ as solvent in all the systems.
Table 1. Binary systems studied in this work.

\begin{tabular}{cc}
\hline System & Mixtures \\
\hline 1 & $\mathrm{C}_{15} \mathrm{H}_{32}-\mathrm{C}_{34} \mathrm{H}_{70}$ \\
2 & $\mathrm{C}_{15} \mathrm{H}_{32}-\mathrm{C}_{36} \mathrm{H}_{74}$ \\
3 & $\mathrm{C}_{15} \mathrm{H}_{32}-\mathrm{C}_{38} \mathrm{H}_{78}$ \\
4 & $\mathrm{C}_{15} \mathrm{H}_{32}-\mathrm{C}_{40} \mathrm{H}_{82}$ \\
\hline
\end{tabular}

Table 2. Correlations used for the estimation of properties of pure n-alkanes.

\begin{tabular}{|c|c|c|c|c|}
\hline Property & Symbol & Equation & & Correlation \\
\hline Fusion enthalpy $(\mathrm{J} / \mathrm{mol})$ & $\Delta H_{f}$ & $\Delta H_{f}=0.597 M T_{f}$ & (1) & Won (1986) \\
\hline $\begin{array}{l}\text { Absolute density } \\
\left(\mathrm{g} / \mathrm{cm}^{3}\right)\end{array}$ & $\rho$ & $\rho=A_{\rho} B_{\rho}^{-\left(1-\frac{T}{C_{\rho}}\right)^{n}}$ & $(2)$ & $\begin{array}{c}\text { Yaws \& Pike } \\
\text { (2009) }\end{array}$ \\
\hline $\begin{array}{c}\text { Dynamic viscosity } \\
\text { (mPa.s) }\end{array}$ & $\eta$ & $\eta=10^{\left(A_{\eta}+\frac{B_{\eta}}{T}+C_{\eta} T+D_{\eta} T^{2}\right)}$ & (3) & $\begin{array}{c}\text { Yaws \& Dang } \\
\text { (2009) }\end{array}$ \\
\hline $\begin{array}{c}\text { Thermal conductivity } \\
(\mathrm{W} / \mathrm{m} . \mathrm{K})\end{array}$ & k & $k=A_{k}+B_{k} T+C_{k} T^{2}$ & (4) & Yaws (2009) \\
\hline $\begin{array}{l}\text { Molar heat capacity } \\
\qquad(\mathrm{J} / \mathrm{mol} . \mathrm{K})\end{array}$ & $\mathrm{Cp}$ & $\begin{array}{c}C_{p}=\boldsymbol{R}\left[U+W\left(\frac{T}{100}\right)+Y\left(\frac{T}{100}\right)^{2}\right] \\
U=\sum_{i=1}^{n_{t}} n_{i} u_{i} \\
W=\sum_{i=1}^{n_{t}} n_{i} w_{i} \\
Y=\sum_{i=1}^{n_{t}} n_{i} y_{i}\end{array}$ & $\begin{array}{l}\text { (5) } \\
(6) \\
(7) \\
(8)\end{array}$ & $\begin{array}{c}\text { Rùzicka- } \\
\text { Domalski } \\
\text { (Poling et al., } \\
\text { 2001) }\end{array}$ \\
\hline
\end{tabular}


Table 3. Correlations used for the estimation of mixture properties (Poling et al., 2001).

\begin{tabular}{|c|c|c|c|c|}
\hline Property & Symbol & Equation & & Correlation \\
\hline $\begin{array}{l}\text { Absolute density } \\
\qquad\left(\mathrm{g} / \mathrm{cm}^{3}\right)\end{array}$ & $\rho_{\mathrm{m}}$ & $\rho_{m}=\frac{\sum_{i} x_{i} M_{i}}{\sum_{i} x_{i} \frac{M_{i}}{\rho_{i}}}$ & (9) & Rule of mixture \\
\hline $\begin{array}{l}\text { Dynamic viscosity } \\
\text { (mPa.s) }\end{array}$ & $\eta_{m}$ & $\begin{aligned} \ln \eta_{m} & =\sum x_{i} \ln \eta_{i}+\frac{1}{2} \sum_{i=1}^{n} \sum_{j=1}^{n} x_{i} x_{j} G_{i j} \\
G_{i j} & =1-\left[1-G_{i j_{298 K}}\right] \frac{573-T}{275}\end{aligned}$ & $\begin{array}{l}(10) \\
(11)\end{array}$ & Grunberg-Nissar \\
\hline $\begin{array}{l}\text { Thermal } \\
\text { conductivity } \\
\text { (W/m.K) }\end{array}$ & $\mathrm{k}_{\mathrm{m}}$ & $k_{m}=\left(\sum_{i} x_{i} k_{i}^{-2}\right)^{-1 / 2}$ & $(12)$ & Vredeveld \\
\hline $\begin{array}{c}\text { Molar heat capacity } \\
(\mathrm{J} / \mathrm{mol} . \mathrm{K})\end{array}$ & $\mathrm{Cp}, \mathrm{m}$ & $C_{p, m}=\sum_{i} x_{i} C_{p, i}$ & (13) & Rùzicka-Domalsk \\
\hline $\begin{array}{l}\text { Diffusion } \\
\text { coefficient } \\
\left(\mathrm{cm}^{2} / \mathrm{s}\right)\end{array}$ & D & $\begin{array}{c}D=13.3 \times 10^{-8}\left(\frac{T^{1.47} \eta_{\text {sol }}^{\lambda}}{V_{A}^{0.71}}\right) \\
\lambda=\left(10.2 / \mathrm{V}_{\mathrm{A}}\right)-0.791\end{array}$ & $\begin{array}{l}(14) \\
(15)\end{array}$ & Hayduk-Minhas \\
\hline
\end{tabular}

\subsection{Estimation of properties of pure $n$ - alkanes and mixtures}

Table 2 lists the methods used in the estimation of physical, thermodynamic, thermal, and transport properties of pure components. Table 3 lists the methods as they were used for the four chosen binary systems.

Fusion and boiling temperature ( $T_{f}$ and $T_{b}$, respectively) of pure components were obtained from experimental data from the literature and are presented in Table 4.

Table 4. Experimental values of $T_{f}$ and $T_{b}$ for alkanes $\mathrm{C}_{15}, \mathrm{C}_{34}, \mathrm{C}_{36}, \mathrm{C}_{38}$, and $\mathrm{C}_{40}$ (Yaws \& Narasimham, 2009).

\begin{tabular}{ccc}
\hline Component & $\boldsymbol{T}_{\boldsymbol{f}}^{\text {exp }}(\mathrm{K})$ & $\boldsymbol{T}_{\boldsymbol{b}}^{\text {exp }}(\mathrm{K})$ \\
\hline $\mathrm{C}_{15} \mathrm{H}_{32}$ & 283.07 & 543.83 \\
$\mathrm{C}_{34} \mathrm{H}_{70}$ & 343.25 & 755.15 \\
$\mathrm{C}_{36} \mathrm{H}_{74}$ & 349.05 & 770.15 \\
$\mathrm{C}_{38} \mathrm{H}_{78}$ & 352.15 & 784.15 \\
$\mathrm{C}_{40} \mathrm{H}_{82}$ & 354.65 & 798.15 \\
\hline
\end{tabular}

\subsection{Solid-liquid equilibrium calculation}

The determination of WAT for the binary systems was carried out using the model proposed by Won (1986), shown in Equation (16):

$\frac{x_{i}^{S}}{x_{i}^{L}}=\frac{\gamma_{i}^{L}}{\gamma_{i}^{S}} \exp \left[\frac{\Delta H_{f, i}}{\boldsymbol{R} T}\left(1-\frac{T}{T_{f, i}}\right)\right]$

If the solution in question is regarded as regular, activity coefficients can be determined as a function of solubility parameters (Won, 1986). Applying this assumption to Equation (16) results in Equation (17), which relates WAT to the molar fraction of paraffin in the liquid phase, $x_{i}^{L}$ :

$$
W A T=T=\frac{V_{i}^{L}\left(\bar{\delta}^{L}-\delta_{i}^{L}\right)^{2}+\Delta H_{f, i}}{-\boldsymbol{R} \ln x_{i}^{L}+\frac{\Delta H_{f, i}}{T_{f, i}}}
$$

\subsection{Deposition modeling}

The following assumptions were applied to the deposition model:

- The flow regime was described as stationary turbulent flow; 
- Concentration profile was effective only in the thermal boundary-layer;

- The properties of solid and liquid paraffin were considered to be the same;

- Molecular diffusion was the sole mechanism for deposition;

- The complex rheology of paraffinic mixtures was not taken into account in the model.

Fick's Law (molecular diffusion) governs mass transfer:

$\vec{J}_{p a r}=-D \frac{d C_{s}}{d T} \nabla T$

Where $\vec{J}_{\text {par }}$ is the paraffin mass flow, D is paraffin diffusion coefficient, and $C_{S}(\mathrm{~T})$ is the paraffin solubility in oil. Considering that the deposit is formed by oil and solidified paraffin, paraffin flux is a fraction of the total deposit flux:

$\vec{J}_{\text {par }}=\psi \vec{J}_{\text {dep }}$

Total deposition flux is given by:

$\vec{J}_{d e p}=-\frac{1}{\psi} D \frac{d C_{s}}{d T} \nabla T$

Where $\psi$ represents the solid fraction of paraffin solids in the deposit.

Deposit consolidation and ablation-related phenomena were taken into account in the model developed in this work. Ablation is a result of drag force action on paraffin molecules located in the deposit, compensating for adhesion. In this work it was assumed that ablation rate is proportional to shear stress at the pipe wall:
$\vec{J}_{a b l}=-A \frac{\tau}{\psi}$

$A$ is an experimental coefficient that may be constant or a function of $\psi$ (in this work $A$ was considered to be constant).

The consolidation of paraffin deposit may be interpreted as a gradual release of confined oil, increasing the value of $\psi$, promoting deposit "hardening". Assuming that the rate at which oil is released by the deposit is related to the velocity gradient at the limit layer and, consequently, to $\tau$, the reduction in the rate of deposit layer thickening will be proportional to the fraction of oil contained in the deposit. The equation of deposit consolidation kinetics used in this work was (Correra et al., 2007):

$\frac{\partial \psi}{\partial t}=\frac{1}{t_{a}}(1-\psi)$

In this equation, $t_{a}$ is the deposit consolidation time, usually much longer than deposition time scale.

Deposition profile, i.e., thickness of deposited layer along pipeline, was obtained via mass balance carried out in the deposit interface, involving molecular diffusion, ablation, and consolidation, resulting in Equation (26).

The equations that constitute the used deposition model are listed in Table 5. The choice for a simplified deposition model, proposed by Correra et al. (2007), was based on the goodness to fit of the referred model to turbulent flow data coming from real field installations.

Table 5. Equations used in the model for deposition under turbulent flow.

\begin{tabular}{lc}
\hline \multicolumn{1}{c}{ Description } & Equation \\
\hline $\begin{array}{l}\text { Temperature profile in } \\
\text { the thermal limit layer }\end{array}$ & $T(r, z, t)=-a(z, t) R_{T}(z, t) \ln \left(\frac{r}{R_{T}(z, t)}\right)+T_{n}(z, t)$ \\
\hline $\begin{array}{l}\text { Temperature profile in } \\
\text { the turbulent nucleus }\end{array}$ & $T(r, z)=\left[T_{\text {in }}-T_{\text {ext }}\right] \exp \left\{-\frac{2 \pi \alpha}{\mu Q} z\right\}\left\{1-\frac{1}{\mu} \ln \left(\frac{r}{R}\right)\right\}+T_{\text {ext }}$ \\
\hline $\begin{array}{c}\text { Thickness of formed } \\
\text { deposit }\end{array}$ & $\left.\sigma_{d} \approx \frac{1}{h R}+\ln \left(\frac{R}{R_{T}}\right)\right]$ \\
\hline$\rho R$ & {$\left[\frac{\left(T_{i n}-T_{\text {ext }}\right)}{\mu} \exp \left\{-\frac{2 \pi \alpha}{\mu Q} z\right\}-\frac{A \eta Q}{\pi \varepsilon_{v} D \beta R^{2}}\right] H\left(W A T-T_{w}\right)$} \\
\hline
\end{tabular}


Table 6. Parameters from Svendsen (1993) used in the simulation.

\begin{tabular}{cc}
\hline Parameter & Value \\
\hline Radius $(\mathrm{m})$ & 0.15 \\
Pipe length $(\mathrm{m})$ & 5000 \\
Flow rate $\left(\mathrm{m}^{3} / \mathrm{s}\right)$ & 0.14 \\
Inlet temperature $(\mathrm{K})$ & 303 \\
External temperature $(\mathrm{K})$ & 278 \\
Density $\left(\mathrm{kg} / \mathrm{m}^{3}\right)$ & $-0.65[\mathrm{~T}(\mathrm{~K})-293]+855$ \\
Reynolds Number & 57970 \\
Paraffin mass fraction & 0.15 \\
\hline
\end{tabular}

\subsection{Deposition simulation}

In order to achieve a better understanding of paraffin deposition as a function of the several variables involved in the process, a software was developed for flow simulations. The software was named DepoSim and was capable of calculating fluid temperature and deposition profiles, using the deposition model described in this work.

The first simulation was carried out using the work of Svendsen (1993) as a reference for comparison with the results found in this work. This choice was based in the lack of experimental parameters reported for the equations that describe the process of deposition in turbulent flow. When using system $3\left(C_{15}-C_{38}\right)$, similar to the Svendsen (1993), the same conditions of flow and temperature reported in the literature were fed into the software. The parameters used in the simulation are shown in Table 6.

Subsequently, a study of deposition for the other binary systems was carried out and the effect of operation temperature on the process of deposition was evaluated. The parameters' radius, pipe length, flow rate, and paraffin fraction mass were fixed for this study.

Table 7. Estimated values of fusion enthalpy for the n-alkanes $\mathrm{C}_{15}, \mathrm{C}_{34}, \mathrm{C}_{36}, \mathrm{C}_{38}$, and $\mathrm{C}_{40}$.

\begin{tabular}{cc}
\hline Component & $\boldsymbol{\Delta H}_{\boldsymbol{f}}^{\text {est }}(\mathbf{k J} / \mathbf{m o l})$ \\
\hline $\mathrm{C}_{15} \mathrm{H}_{32}$ & 36.153 \\
$\mathrm{C}_{34} \mathrm{H}_{70}$ & 98.646 \\
$\mathrm{C}_{36} \mathrm{H}_{74}$ & 105.322 \\
$\mathrm{C}_{38} \mathrm{H}_{78}$ & 112.048 \\
$\mathrm{C}_{40} \mathrm{H}_{82}$ & 188.803 \\
\hline
\end{tabular}

\section{RESULTS AND DISCUSSION}

\subsection{Estimation of properties of pure n- alkanes and mixtures}

Table 7 lists estimated values of fusion enthalpy for the n-alkanes chosen for this study. The estimated value of $\Delta \mathrm{H}_{\mathrm{f}}$ for $\mathrm{C}_{15}$ presented a deviation of $4.5 \%$, when compared to the one experimentally obtained by Yaws and Lin (2009). This deviation can be considered satisfactory for the developed deposition modeling, so that the extrapolation of the correlation of Won (1986) was considered adequate to estimate the values of fusion enthalpy for the other $n$-alkanes.

Density, viscosity, thermal conductivity, and calorific capacity were evaluated as a function of the range of operation temperature. To verify estimated values, experimental data for these properties were extracted form DIPPR database, using the software DIADEM Database v.1.1 (This program only makes available data for $\mathrm{C}_{15}$ ). Table 8 and Table 9 present experimental and estimated values (as well as the percent deviations) for $C_{15}$. As a result, correlation was validated for the component $\mathrm{C}_{15}$ and an extrapolation was assumed for the other components.

Density, viscosity, thermal conductivity, and heat capacity for the four binary systems were plotted as a function of operation temperature range. The graphics obtained for the four systems are shown in Figures 2 to 5 .

From the figures, one can observe that density and viscosity were more affected by molar mass when compared to thermal conductivity and calorific capacity. On the other hand, the difference between any property values in binary systems was 
Table 8. Comparison between the values of density and viscosity obtained for $\mathrm{C}_{15}$ using DIPPR and the correlations of Yaws-Pike and Yaws-Dang.

\begin{tabular}{|c|c|c|c|c|c|c|}
\hline $\mathrm{T}(\mathrm{K})$ & $\begin{array}{l}\rho^{D I P P R} \\
\left(\mathrm{~kg} / \mathrm{m}^{3}\right)\end{array}$ & $\begin{array}{c}\rho^{Y \& P} \\
\left(\mathrm{~kg} / \mathrm{m}^{3}\right)\end{array}$ & $\begin{array}{c}\text { |Deviation | } \\
\text { (\%) }\end{array}$ & $\begin{array}{l}\eta^{D I P P R} \\
\left(\mathrm{~kg} / \mathrm{m}^{3}\right)\end{array}$ & $\begin{array}{c}\eta^{Y \& D} \\
\left(\mathrm{~kg} / \mathrm{m}^{3}\right)\end{array}$ & $\begin{array}{c}\text { |Deviation | } \\
\text { (\%) }\end{array}$ \\
\hline 285.5 & 772.9884 & 773.5839 & 0.08 & 3.310 & 3.398 & 2.7 \\
\hline 288.0 & 771.5014 & 771.8942 & 0.05 & 3.130 & 3.204 & 2.4 \\
\hline 290.5 & 769.8021 & 770.2012 & 0.05 & 2.970 & 3.025 & 1.8 \\
\hline 293.0 & 768.1028 & 768.5049 & 0.05 & 2.820 & 2.859 & 1.4 \\
\hline 295.5 & 766.4034 & 766.8054 & 0.05 & 2.680 & 2.707 & 1.0 \\
\hline 298.0 & 764.7041 & 765.1027 & 0.05 & 2.550 & 2.566 & 0.6 \\
\hline 300.5 & 763.2172 & 763.3965 & 0.02 & 2.430 & 2.435 & 0.2 \\
\hline 303.0 & 761.5178 & 761.687 & 0.02 & 2.310 & 2.314 & 0.2 \\
\hline
\end{tabular}

Table 9. Comparison between the values of thermal conductivity and calorific capacity obtained for $\mathrm{C}_{15}$ using DIPPR and the correlations of Yaws and Rùzicka-Domalski.

\begin{tabular}{|c|c|c|c|c|c|c|}
\hline $\mathrm{T}(\mathrm{K})$ & $\begin{array}{c}k^{D I P P R} \\
(\mathrm{~W} / \mathrm{m} . \mathrm{K})\end{array}$ & $k^{Y}$ (W/m.K) & $\begin{array}{c}\text { |Deviation | } \\
\text { (\%) }\end{array}$ & $\begin{array}{l}C_{p}^{D I P P R} \\
\text { (J/kg.K) }\end{array}$ & $\begin{array}{c}C_{p}{ }^{R \& D} \\
\text { (J/kg.K) }\end{array}$ & $\begin{array}{c}\text { |Deviation | } \\
\text { (\%) }\end{array}$ \\
\hline 285.5 & 0.1439 & 0.1425 & 0.99 & 2180.09 & 2135.69 & 2.04 \\
\hline 288.0 & 0.1434 & 0.1420 & 0.97 & 2187.10 & 2144.30 & 1.96 \\
\hline 290.5 & 0.1428 & 0.1415 & 0.94 & 2194.12 & 2153.00 & 1.87 \\
\hline 293.0 & 0.1423 & 0.1410 & 0.91 & 2201.23 & 2161.79 & 1.79 \\
\hline 295.5 & 0.1417 & 0.1405 & 0.87 & 2208.34 & 2170.66 & 1.71 \\
\hline 298.0 & 0.1412 & 0.1400 & 0.85 & 2215.54 & 2179.63 & 1.62 \\
\hline 300.5 & 0.1407 & 0.1395 & 0.82 & 2222.74 & 2188.67 & 1.53 \\
\hline 303.0 & 0.1401 & 0.1390 & 0.79 & 2229.99 & 2197.81 & 1.44 \\
\hline
\end{tabular}

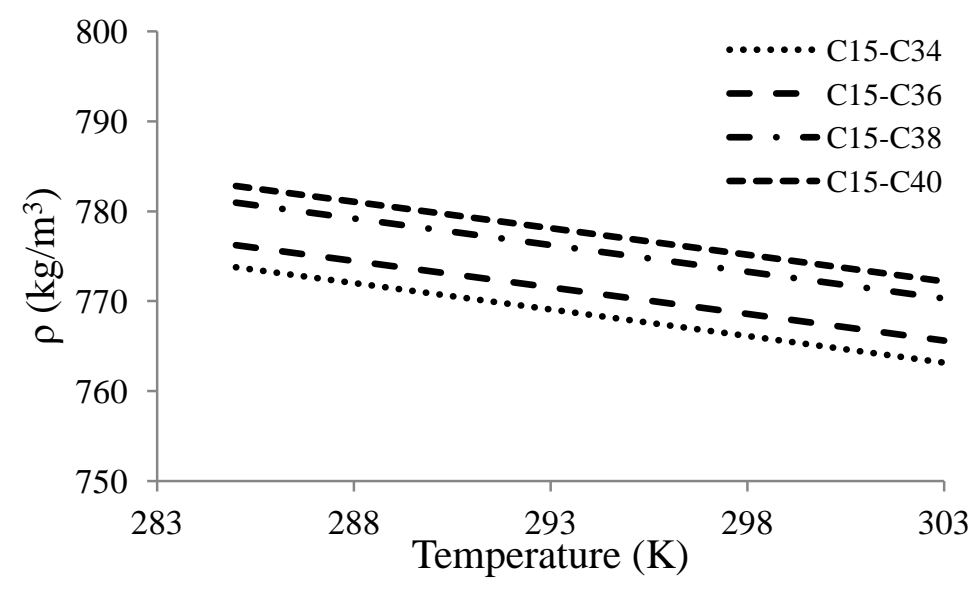

Figure 2. Densities of binary paraffinic systems as a function of temperature.

rather small, due to the small mass fraction of paraffin in the system (0.15).

\subsection{Solubility curve}

Molar mass, melting temperature, and molar fraction of paraffinic component that deposit affect phase equilibriums. A value increase promotes an increase in WAT, increasing paraffin precipitation. Table 10 shows WAT and solubility (at $303 \mathrm{~K}$ ) values for the systems studied.

Solubility curves for the paraffins as a function of temperature are shown in Figure 6. 


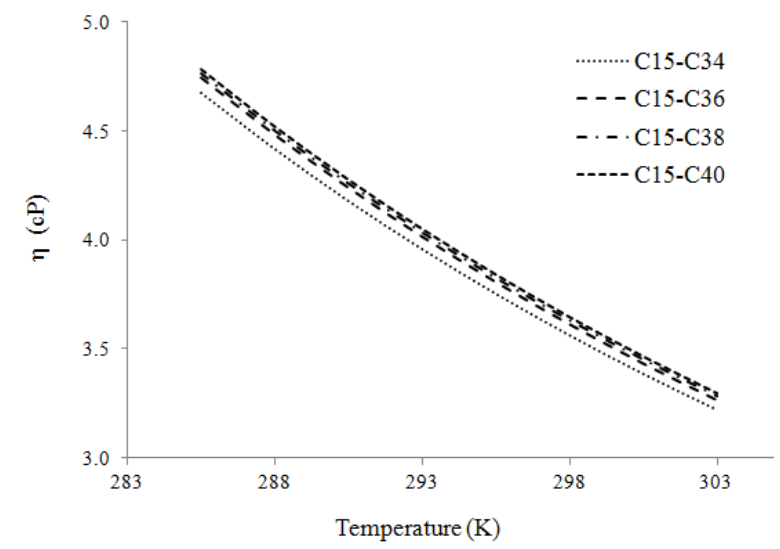

Figure 3. Viscosities of binary paraffinic systems as a function of temperature.

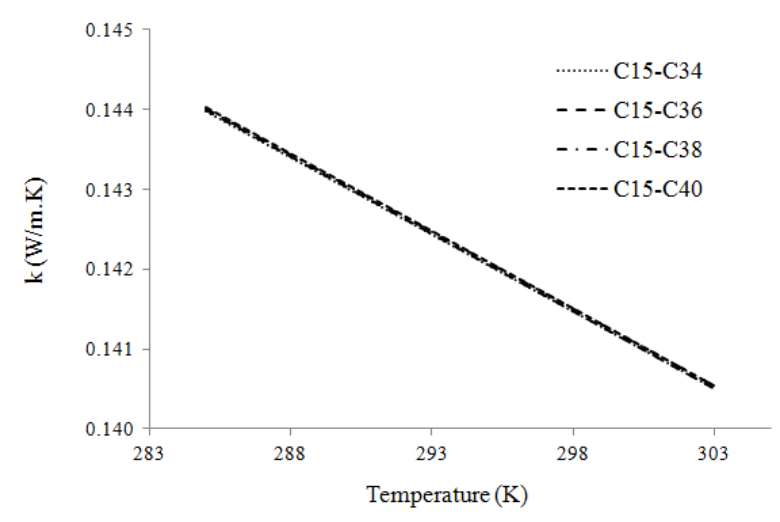

Figure 4. Thermal conductivities of binary paraffinic systems as a function of temperature.

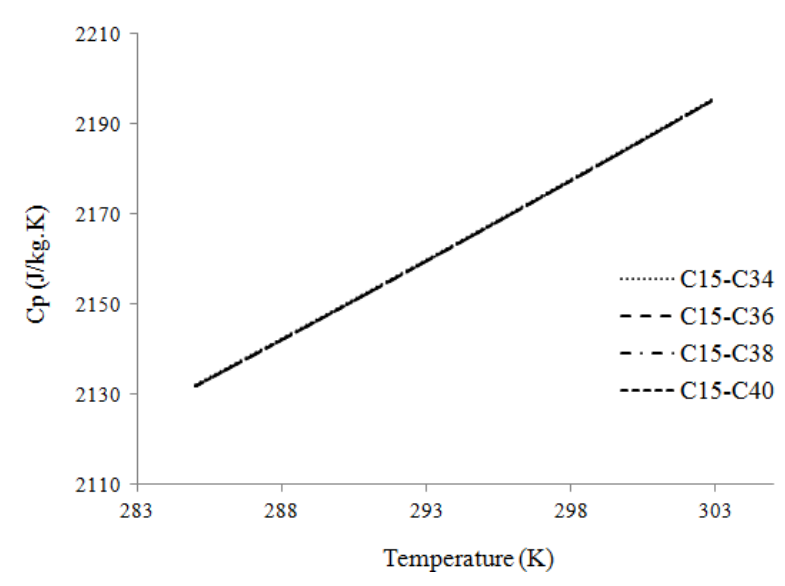

Figure 5. Heat capacities of binary paraffinic systems as a function of temperature.

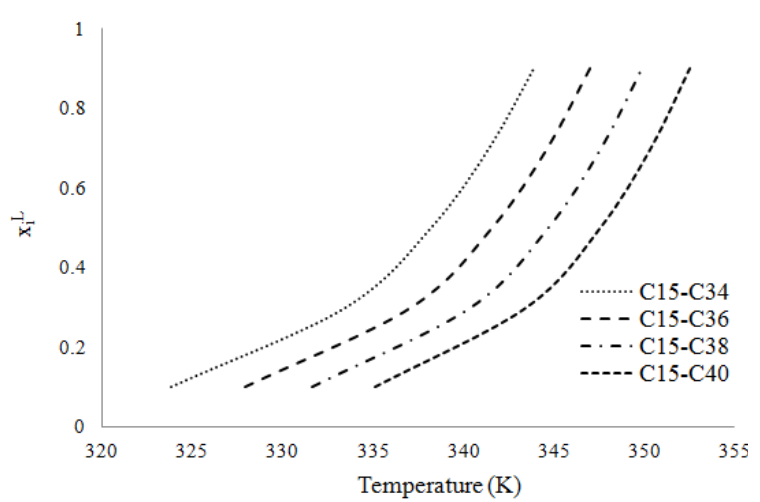

Figure 6. Paraffin solubility as a function of temperature for systems $1,2,3$, and 4 .

The calculation of solubility curves is important because their derivatives are used in the calculation of paraffinic deposition flux via molecular diffusion mechanism.

\subsection{Simulation of paraffin deposition}

A typical implemented DepoSim deposition simulator window is presented in Figure 7. When executed, the software presents a window containing areas for the insertion of data, presentation of results, as well as icons for performing calculation and graphic plotting.

For a simulation carried out using system 3, composed of a $\mathrm{C}_{15}-\mathrm{C}_{38}$ mixture, with the same conditions of flow and temperature already reported in the literature (Svendsen, 1993), the deposition profile, presented in Figure 8, indicates how deposit thickness varies as a function of pipe length after 30 days of flow. The thickness profile curve obtained in this work is less extended and presents a behavior different from the one reported by Svendsen (1993). This difference can be explained as a consequence of the model used

Table 10. WAT and $x_{i}^{L}$ (at $303 \mathrm{~K}$ ) values for binary paraffinic systems obtained by Equation.

\begin{tabular}{ccc}
\hline System & WAT (K) & $\mathbf{x}_{\mathbf{i}}{ }^{\mathrm{L}}$ (303K) \\
\hline 1 & 320.2 & $8.74 \mathrm{E}-3$ \\
2 & 324.5 & $6.52 \mathrm{E}-3$ \\
3 & 328.4 & $3.56 \mathrm{E}-3$ \\
4 & 332 & $1.5 \mathrm{E}-3$ \\
\hline
\end{tabular}




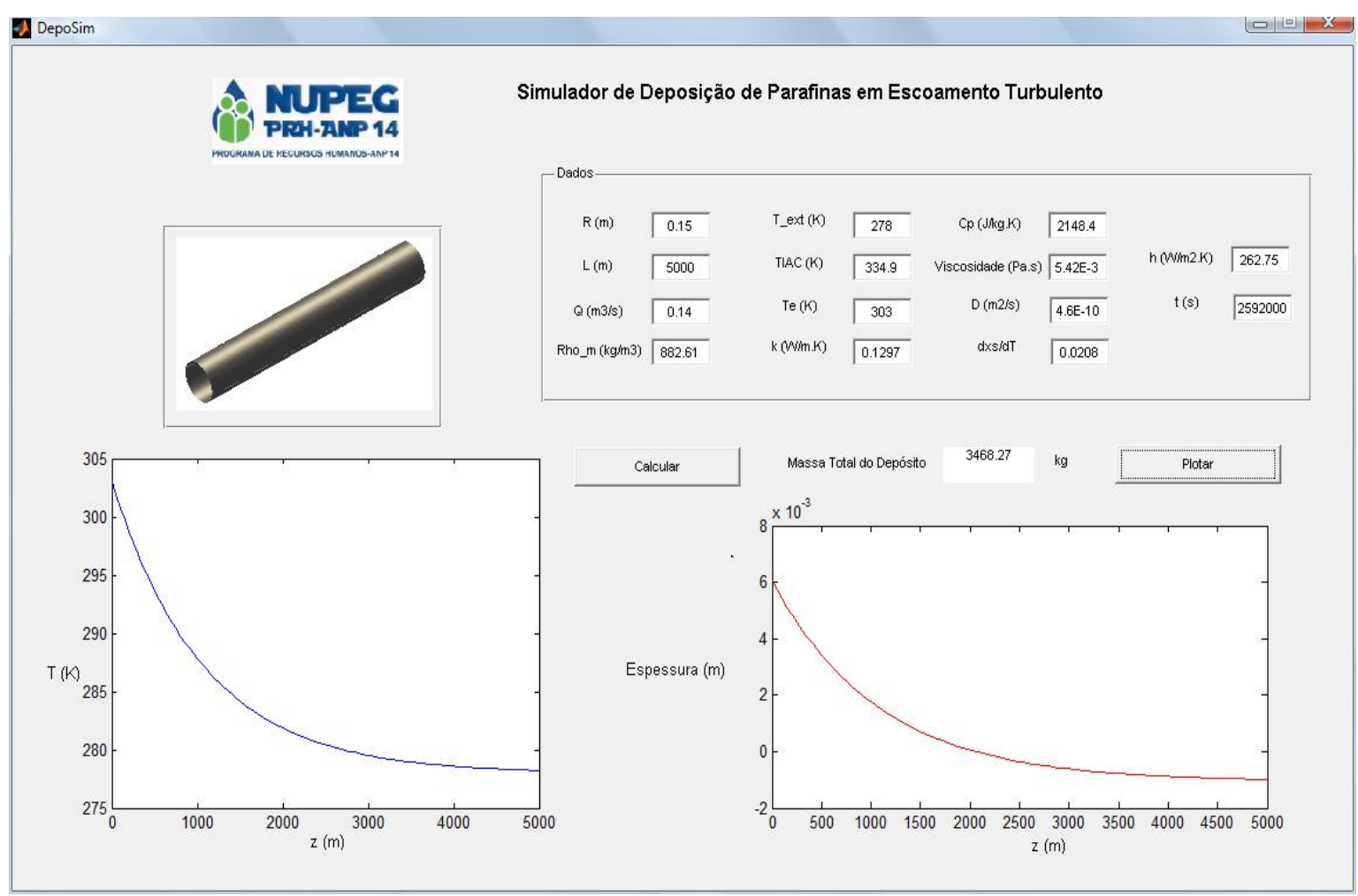

Figure 7. Window of deposition simulator software, DepoSim, developed using MATLAB.

in the present work, which takes into account ablation that promotes a higher deposit thickness reduction. More specifically, when the deposit is formed on a pipe wall, the inner pipe radius decreases, resulting in an increase of fluid velocity and shear, increasing, consequently, the effect of ablation.

All the results obtained in this work considered the ablation phenomena, similarly to the ones done in experimental terms by Pan et al. (2009)

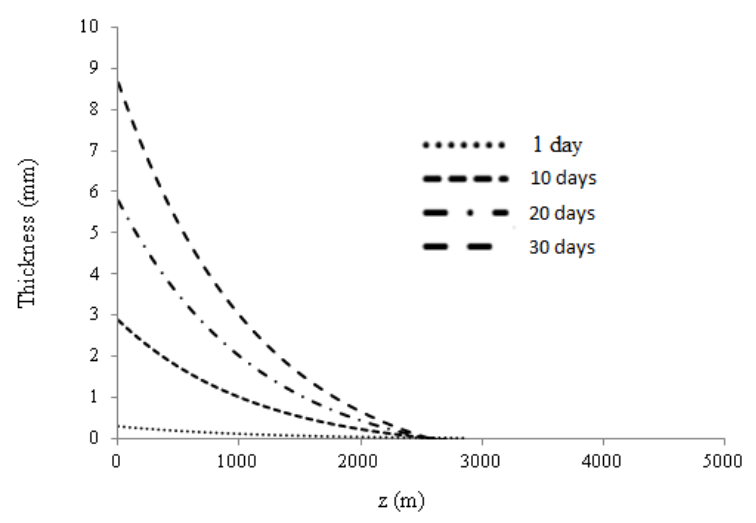

Figure 8. Deposition profiles for system 3. and Tiwary and Mehrotra (2009). In both works, turbulence was shown to decrease deposit thickness, in contrast with the work already cited of Svendsen (1993).

From the observations, maximum thickness always occurs next to pipe entrance; this is consistent with the fact that as oil enters the pipe it is saturated with paraffin crystals.

\subsubsection{Influence of paraffin-solvent composition}

As the paraffin molar mass is increased, its melting point increases, resulting in the decrease of paraffin solubility and an increase in WAT. Simulations were carried out in systems 1, 2, 3, and 4 , to verify how these physicochemical facts appear in the simulation results for deposition. The results are displayed in Figures 9 and Figure 10.

Temperature profiles in nucleus (Figure 9), obtained by Equation 25, are similar for the studied binary systems. This is a coherent result, as the estimated thermal properties for the systems are very close to each other. 


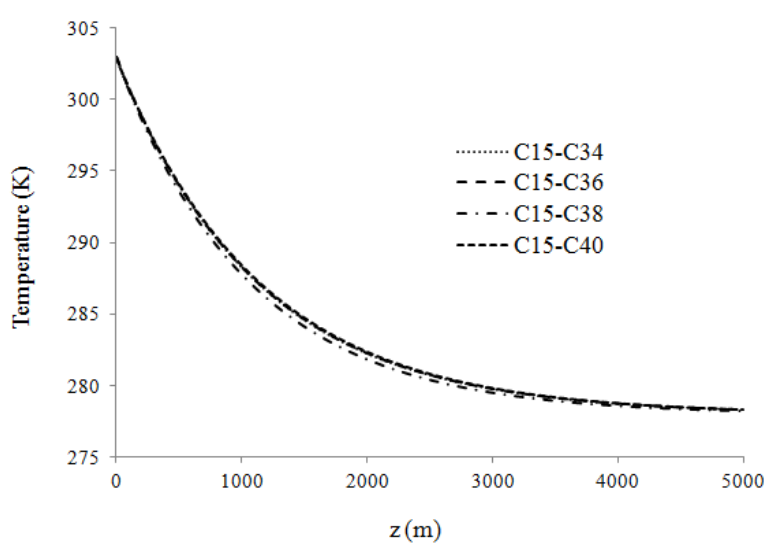

Figure 9. Temperature profile in the turbulent nucleus for some binary systems after 30 days.

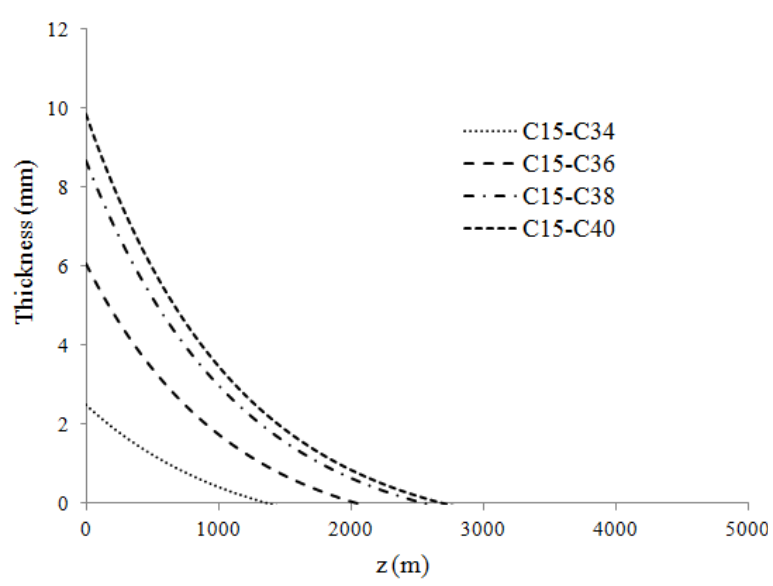

Figure 10. Thickness profiles for some binary systems after 30 days.

Regarding the amount of deposited paraffin, system $4\left(\mathrm{C}_{15}-\mathrm{C}_{40}\right)$ was the one to present the highest amount of deposit during flow, yielding a deposit thickness of $10 \mathrm{~mm}$, according to Figures 10. The results also show that as molar mass increases, a higher amount of deposit is formed, stressing its influence (and the influence of WAT, consequently) on deposit formation.

\subsubsection{Effect of inlet $\left(T_{\text {in }}\right)$ and external temperature ( $\left.T_{\text {ext }}\right)$}

Some experimental studies have reported that the amount of deposit may decrease or increase with the increase in the difference between the oil and surrounding temperatures (Huang et al., 2011b). The exact behavior will depend on diffusion parameters as well as on the difference between paraffin equilibrium concentrations in oil and on pipe wall (solubility curve). These two parameters influence paraffins mass flow and, consequently, the amount of deposit formed.

The evaluation of the amount of deposited paraffin for system 3, with the change in oil temperature in pipe inlet $\left(T_{\text {in }}\right)$ and external temperature $\left(T_{\text {ext }}\right)$, was performed through simulations using DepoSim. The results are presented in Figure 11 and Figure 12.

Figure 11 shows that as oil inlet temperature is increased, the amount of deposit increases. That can be explained as the result of temperature gradient increase and, consequently, of the deposition mass flux, due to the increase in paraffin diffusivity towards wall pipe and the behavior exhibited by the solubility curve.

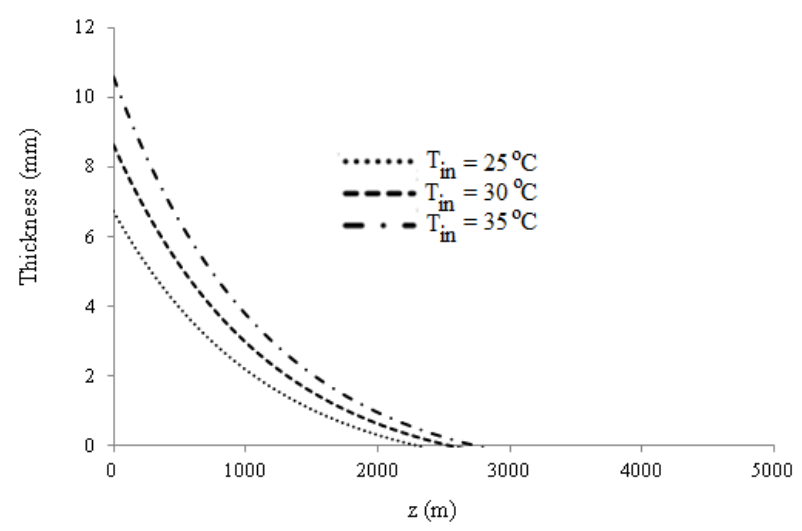

Figure 11. Paraffin thickness profile for system 3 after 30 days, varying the pipe inlet temperature.

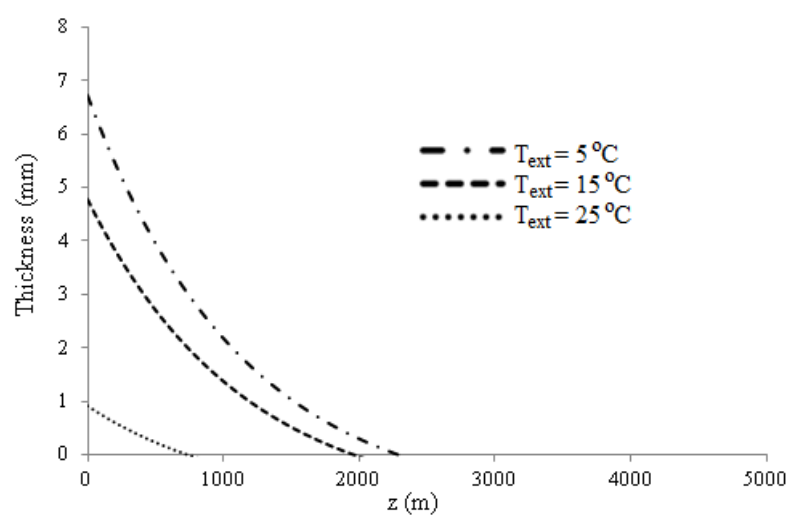

Figure 12. Paraffin thickness profile for system after 30 days, for different external temperatures. 
According to the solubility curve for system 6 (Figure 6), the concentrations of paraffin in oil is superior to the concentration on the wall, resulting in a higher difference in concentration (stronger mass deposition driving force).

Finally, the expected result for the increase in external temperature is the decrease in the amount of formed deposit, as a result of the decrease in mass deposition flux. The results obtained confirm this hypothesis and can be visualized in Figure 12.

The results for the effect of $T_{\text {in }}$ and $T_{\text {ext }}$ on the deposit thickness are in good agreement with the previously reported results (Arumugam et al., 2013; Haj-Shafiei et al., 2014). The deposit thickness profiles obtained for the simulated case is characteristic of the cold flow regime, when there are paraffin crystals suspended in the liquid phase $\left(T_{\text {in }}<\right.$ WAT), and under turbulent flow. However, in the hot flow regime ( $T_{\text {in }}>$ WAT), the deposit thickness increases along the pipeline length until reaching a maximum at the transition from hot flow to cold flow, and then decreases in the cold flow regime.

\section{CONCLUSIONS}

The simulation of different operation conditions using the software DepoSim could be used to get a better understanding of the influence of mixture composition and operation temperatures in the amount of formed deposit as well as the role of solubility curve in the deposition mass flux. The chosen model to describe paraffin deposition seemed adequate to the simulated turbulent flow, as the obtained results presented a behavior closer to real paraffinic oil transport operations. The results of this study have also shown that the process of paraffin deposition has temperature gradient as the main driving force, directly influencing deposit formation.

The methodology developed in this work for simulating the deposition of paraffins, using established correlations to estimate the properties of paraffin-solvent mixtures has the potential to be applied to more comprehensive studies, including ones on multicomponent mixtures.

\section{ACKNOWLEDGMENTS}

The authors wish to thank Universidade Federal do Amazonas and Programa de Pós-Graduação em Engenharia Química da UFRN, Petrobras, ANP, FINEP, MCT, and PFRH-14 ANP for the financial support.

\section{NOMENCLATURE}

\section{Symbols:}

a Coefficient of temperature profile

$A_{\rho} \quad$ Yaws-Pike parameter of density correlation

$A_{k} \quad$ Yaws parameter for thermal conductivity

$A_{\eta} \quad$ Yaws-Dang parameter for viscosity

$B_{\rho} \quad$ Yaws-Pike parameter for density

$B_{k} \quad$ Yaws parameter for thermal conductivity

$B_{\eta} \quad$ Yaws-Dang parameter for viscosity

$C_{\rho} \quad$ Yaws-Pike parameter for density

$C_{k} \quad$ Yaws parameter for thermal conductivity

$C_{\eta} \quad$ Yaws-Dang parameter for viscosity

Cp Molar calorific capacity (J/mol.K)

$D$ Diffusion coefficient $\left(\mathrm{m}^{2} / \mathrm{s}\right)$

Yaws-Dang correlation parameter for

$D_{\eta} \quad$ viscosity correlation

G Interaction parameter for Grunberg-Nissan

correlation

$\Delta H \quad$ Molar enthalpy variation $(\mathrm{J} / \mathrm{mol})$

j Mass flux $\left(\mathrm{kg} / \mathrm{m}^{2} . \mathrm{s}\right)$

$h$ Convective coefficient of heat transfer

$L \quad$ Pipe length

$n_{\rho} \quad$ Yaws-Pike correlation parameter

$n_{t} \quad$ Total number of groups in molecule

$m \quad$ Mass $(\mathrm{kg})$

$M \quad$ Molar mass $(\mathrm{kg} / \mathrm{kmol})$

$N_{C} \quad$ Number of carbon atoms

$P$ Pressure $(\mathrm{Pa})$

$Q \quad$ Volume flow rate $\left(\mathrm{m}^{3} / \mathrm{s}\right)$

$\boldsymbol{R} \quad$ Universal gas constant (8.314 J/mol.K)

$R \quad$ Radius (m)

$R_{T} \quad$ Radius at which velocity is constant $(\mathrm{m})$

Re Reynolds number

$r$ Radial coordinate

$k \quad$ Thermal conductivity $\left(\mathrm{W} / \mathrm{m}^{2} . \mathrm{K}\right)$

$t$ Time (s) 


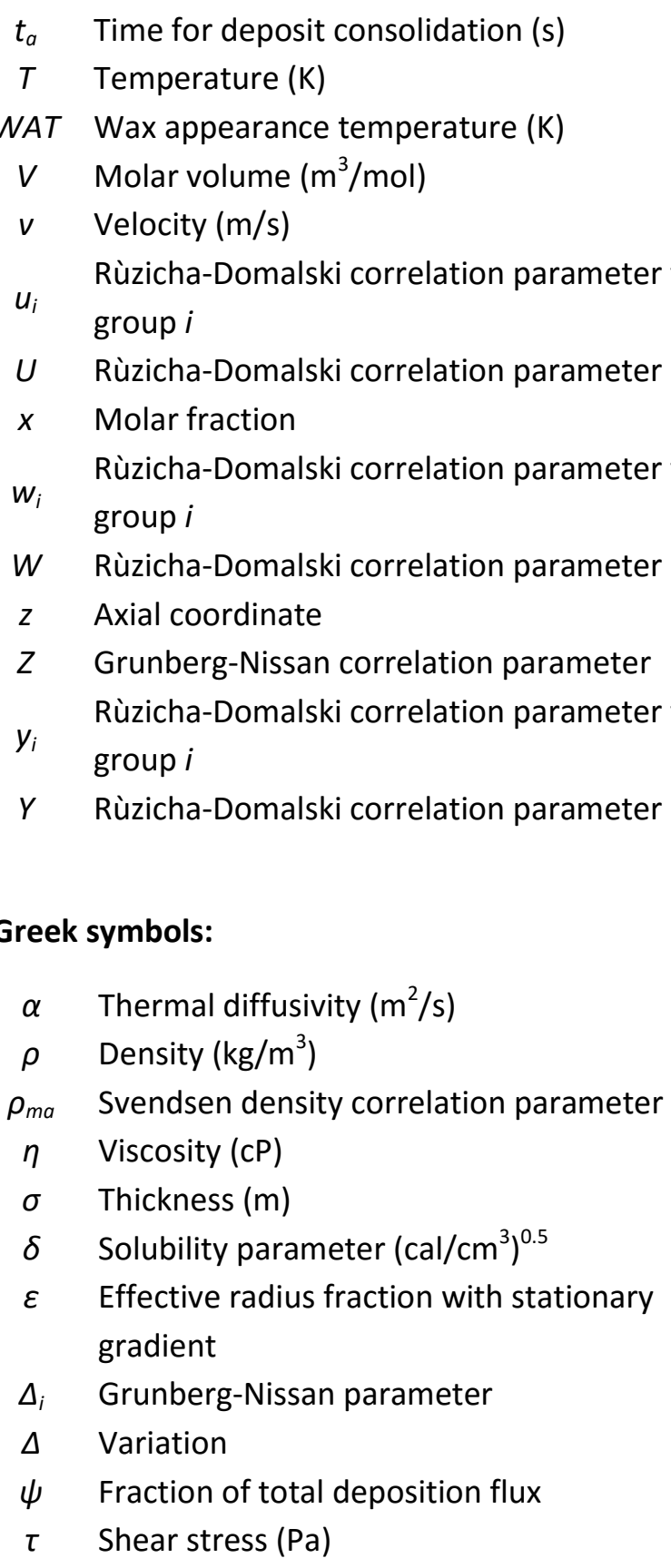

\section{Superscripts:}

$\begin{array}{ll}\text { DIPPR } & \text { DIPPR database } \\ \text { Exp } & \text { Experimental } \\ \text { est } & \text { Estimated } \\ L & \text { Liquid phase } \\ S & \text { Solid phase } \\ Y & \text { Yaws correlation parameter } \\ Y \& D & \text { Yaws-Dang correlation parameter } \\ Y \& P & \text { Yaws-Pike correlation parameter }\end{array}$

\section{Subscripts:}

$\begin{array}{ll}a b l & \text { Ablation } \\ b & \text { At boiling point } \\ d & \text { Deposit } \\ \text { dep } & \text { Deposition } \\ e x t & \text { External } \\ f & \text { Fusion } \\ i & \text { Component } i \\ \text { in } & \text { Inlet } \\ j & \text { Component } j \\ m & \text { Mixture } \\ n & \text { Nucleus } \\ m o l & \text { Relative to molecular diffusion } \\ o & \text { Initial } \\ p & \text { Wall } \\ s & \text { Solid } \\ \text { sol } & \text { Solvent } \\ T & \text { Thermal } \\ v & \text { Velocity }\end{array}$

\section{REFERENCES}

Akbarzadeh, K.; Zougari, M. Introduction to a novel approach for modeling wax deposition in fluid flows. 1. Taylor-Couette system. Industrial \& Engineering Chemistry Research, v. 47, p. 953-963, 2008. http://dx.doi.org/10.1021/ie0711325

Arumugam, S.; Kasumu, A. S.; Mehrotra, A. K. Modeling of solids deposition from waxy mixtures in hot flow and cold flow regimes in a pipeline operating under turbulent flow. Energy \& Fuels, v. 27, p. 6477-90, 2013. http://dx.doi.org/10.1021/ef401315m

Bagatin, R.; Busto, C.; Correra, S.; Margarone, M.; Carniani, C. Wax modelling: there is need for alternatives. In: SPE Russian oil and gas technical conference and exhibition, 2008, Moscow.

Cabanillas, J. P.; Leiroz, A. T.; Azevedo, L. F. A. Wax Deposition in the Presence of Suspended Crystals. Energy \& Fuels, v. 30, p. 1-11, 2016. http://dx.doi.org/10.1021/acs.energyfuels.5b02344

Correra, S.; Fasano, A.; Fusi, L.; Merino-Garcia, D. Calculating deposit formation in the pipelining of waxy crude oils. Meccanica, v. 42, p. 149-165, 2007. http://dx.doi.org/10.1007/s11012-006-9028-4 
Eskin, D.; Ratulowki, J.; Akbarzadeh, K. A model of wax deposit layer formation. Chemical Engineering Science, v. 97, p. 311-319, 2013. http://dx.doi.org/10.1016/i.ces.2013.04.040

Haj-Shafiei, S.; Serafini, D.; Mehrotra, A. K. A steady-state heatt ransfer model for solids deposition from waxy mixtures in a pipeline. Fuel, v.137, p. 346-359, 2014.

http://dx.doi.org/10.1016/j.fuel.2014.07.098

Huang, Z.; Lee, H. S.; Senra, M.; Fogler, H. S. A Fundamental Model of Wax Deposition in Subsea Oil Pipelines. Aiche Journal, v. 57, p. 2955-2964, 2011a. http://dx.doi.org/10.1002/aic.12517

Huang, Z.; Lu, Y.; Hoffmann, R.; Amundsen, L.; Fogler, H. S. The Effect of Operating Temperatures on Wax Deposition. Energy \& Fuels, v. 25, p. 51805188, 2011b. http://dx.doi.org/10.1021/ef201048w

Pan, S.; Zhu, J.; Zhang, D.; Razouki, A.; Talbot, M.; Wierzchowski, S. Cases Studies on Simulation of Wax Deposition in Pipelines. In: International Petroleum Technology Conference, 2009, Doha, Qatar. http://dx.doi.org/10.2523/13420-MS

Poling, B. E.; Prausnitz, J. M.; O'Connell, J. P. Properties of gases and liquids. New York: McGraw-Hill Education, 2001.

Ramirez-Jaramillo, E.; Lira-Galeana, C.; Manero, O. Modeling wax deposition in pipelines. Petroleum Science and Technology, v. 22, p. 821861, 2004. http://dx.doi.org/10.1081/LFT-120038726

Soedarmo, A. A.; Daraboina, N.; Lee, H. S.; Sarica, C. Microscopic Study of Wax PrecipitationStatic Conditions. Energy \& Fuels, v. 30, p. 954-96, 2016.

http://dx.doi.org/10.1021/acs.energyfuels.5b02653

Svendsen, J. A. Mathematical-Modeling of Wax Deposition in Oil Pipeline Systems. AIChE Journal, v. 39, p. 1377-1388, 1993.

http://dx.doi.org/10.1002/aic.690390815
Tiwary, R.; Mehrotra, A. K. Deposition from Wax-Solvent Mixtures under Turbulent Flow: Effects of Shear Rate and Time on Deposit Properties. Energy \& Fuels, v.23, p. 1299-1310, 2009. http://dx.doi.org/10.1021/ef800591p

Wang, W.; Huang, Q. Prediction for wax deposition in oil pipelines validated by field pigging. Journal of the Energy Institute, v. 87, p. 196-207, 2014. http://dx.doi.org/10.1016/j.joei.2014.03.013

Won, K. W. Thermodynamics for Solid SolutionLiquid-Vapor Equilibria - Wax Phase Formation from Heavy Hydrocarbon Mixtures. Fluid Phase Equilibria, v. 30, p. 265-279, 1986.

http://dx.doi.org/10.1016/0378-3812(86)80061-9

Yaws, C. L. Thermal conductivity of liquids organic compounds. Transport properties of chemical and hydrocarbons, C.L. Yaws, Editor. New York: William Andrew Publishing, 2009.

Yaws, C. L.; Dang, L. L. X. Viscosity of liquids organic compounds. Transport properties of chemical and hydrocarbons, C.L. Yaws, Editor. New York: William Andrew Publishing, 2009.

Yaws, C. L.; Lin, S. C. Enthalpy of fusion at freezing point - organic compounds. Thermophysical properties of chemical and hydrocarbons, C.L. Yaws, Editor. New York: William Andrew Publishing, 2009.

Yaws, C. L.; Narasimham, P.K. Critical properties and acentric factor - organic compounds. Thermophysical properties of chemical and hydrocarbons, C.L. Yaws, Editor. New York: William Andrew Publishing, 2009.

Yaws, C. L.; Pike, R. W. Density of liquids organic compounds. Thermophysical properties of chemical and hydrocarbons, C.L. Yaws, Editor. New York: William Andrew Publishing, 2009. 